\title{
Trailing end-point phenotype of Candida spp. in antifungal susceptibility testing to fluconazole is eliminated by altering incubation temperature
}

According to the Clinical and Laboratory Standards Institute (CLSI) (formerly the

National Committee for Clinical Laboratory Standards) standardized method for antifungal susceptibility testing M27-A2, the MIC for fluconazole is defined as the lowest concentration of drug causing an $80 \%$ inhibition of growth relative to a drug-free control (CLSI, 2002). Proposed breakpoints suggest that susceptible isolates have an MIC $\leqslant 8 \mu \mathrm{g} \mathrm{ml}^{-1}$, susceptible-dose dependent isolates have an MIC of $16-32 \mu \mathrm{g} \mathrm{ml}^{-1}$ and resistant isolates have an MIC $\geqslant 64 \mu \mathrm{g} \mathrm{ml}^{-1}$ (CLSI, 2002). Standard testing reports an MIC at $48 \mathrm{~h}$, and this result is usually within 1-2 doubling dilutions of the $24 \mathrm{~h}$ value. Most isolates of Candida albicans are susceptible to fluconazole with a $48 \mathrm{~h} \mathrm{MIC} \leqslant 1 \mu \mathrm{g} \mathrm{ml}^{-1}$ (Pfaller \& Diekema, 2004). However, when tested by the CLSI method, certain isolates have been found to be susceptible at $24 \mathrm{~h}$, usually with an MIC $\leqslant 1 \mu \mathrm{g} \mathrm{ml}^{-1}$, but highly resistant at $48 \mathrm{~h}$ with an MIC $\geqslant 64 \mu \mathrm{g} \mathrm{ml}^{-1}$, which may be referred to as a trailing end point or tolerance (Pfaller \& Diekema, 2004). In one study, $\mathrm{pH}$ was found to affect trailing in certain isolates (Marr et al., 1999). Mechanisms have been proposed to explain trailing, including activation of calcineurin and altered regulation of genes mediating resistance (Sanglard et al., 2003; Lee et al., 2004). Various studies have suggested that these isolates are actually clinically susceptible (Revankar et al., 1998; Rex et al., 1998). Other Candida species may also demonstrate trailing end points. We evaluated whether altering the incubation temperature in the CLSI method may affect the in vitro susceptibility testing of such isolates to fluconazole. The clinical isolates used were known to exhibit trailing end points by previous testing.

Strains used in this study were all clinical isolates, primarily from human immunodeficiency virus positive patients with oropharyngeal candidiasis. Fourteen isolates were studied, eight with trailing end points (six C. albicans, one Candida tropicalis, one Candida glabrata), three susceptible (all C. albicans) (MIC

$<8 \mu \mathrm{g} \mathrm{ml}^{-1}$ ) and three non-susceptible (one C. albicans, one C. glabrata, one Candida krusei) (MIC $\geqslant 16 \mu \mathrm{g} \mathrm{ml}^{-1}$ ). Isolates were stored in sterile distilled water and subcultured on Sabouraud dextrose agar for $48 \mathrm{~h}$ prior to antifungal susceptibility testing. Susceptibility to fluconazole was tested by the CLSI method $\mathrm{M}-27 \mathrm{~A} 2$, with temperature adjusted to 25 and $42{ }^{\circ} \mathrm{C}$ versus $35{ }^{\circ} \mathrm{C}$ as per the CLSI method. An MIC $\leqslant 8 \mu \mathrm{g} \mathrm{ml}^{-1}$ at $48 \mathrm{~h}$ was considered susceptible, and $\geqslant 16 \mu \mathrm{g} \mathrm{ml}^{-1}$ was considered non-susceptible. A trailing phenotype for fluconazole was an MIC $<8 \mu \mathrm{g} \mathrm{ml}^{-1}$ at $24 \mathrm{~h}$ and $\geqslant 64 \mu \mathrm{g} \mathrm{ml}^{-1}$ at $48 \mathrm{~h}$. Growth rates of the isolates were assessed by taking hourly optical density measurements with a spectrophotometer for $12 \mathrm{~h}$ at $530 \mathrm{~nm}$. Isolates were incubated at $35{ }^{\circ} \mathrm{C}$ in RPMI media. Measurements were plotted on semi-logarithmic graph paper and doubling times determined by the slope of the growth curve in exponential phase.

All testing with variations in the standard CLSI method was done with fluconazole. Experiments were performed in triplicate. Isolates were initially tested at the standard temperature of $35{ }^{\circ} \mathrm{C}$, and then were retested at 25 and $42{ }^{\circ} \mathrm{C}$. All eight isolates that exhibited trailing at $35{ }^{\circ} \mathrm{C}$ lost the phenotype (appeared susceptible) at 25 and $42{ }^{\circ} \mathrm{C}$. No differences were observed between results at 25 and $42{ }^{\circ} \mathrm{C}$. The MICs of susceptible and resistant isolates did not change more than two dilutions. As different variables that may have had an effect on growth appeared to eliminate the trailing effect, we considered whether trailing isolates had a more rapid growth rate than non-trailing isolates. However, the mean doubling time of the trailing isolates was $89 \mathrm{~min}$ and that of the non-trailing isolates was $95 \mathrm{~min}$, which was not statistically different.

The current standardized antifungal susceptibility testing method may produce trailing end points in certain isolates of Candida. As this is observed consistently, it may be a fundamental characteristic of these isolates. Trailing is interpreted by the CLSI method as resistance, though testing by other in vitro methods, animal models and clinical experience reveals these isolates to be susceptible (Marr et al., 1999; Revankar et al., 1998; Rex et al., 1998). The latest reference method also suggests that using the $24 \mathrm{~h}$ result may be more appropriate for such isolates (CLSI, 2002). We have shown that alteration of temperature in the testing methodology eliminates the occurrence of the trailing end point. When other isolates, which did not exhibit trailing end points, were tested under the same altered conditions, no significant change was seen in their susceptibilities. The reason for such dramatic changes in MICs for trailing isolates is not clear, but does not appear to be related to altered growth rates. However, these conditions may affect the expression of certain genes that have been associated with the trailing phenomenon. Ultimately, determining the optimal method to test and report the susceptibilities of trailing isolates will improve the correlation between in vitro testing and clinical outcome.

\section{Acknowledgements}

This work was funded through an unrestricted educational grant by Pfizer, Inc.

\section{Agrawal, ${ }^{1} \dagger$ T. F. Patterson, ${ }^{2}$ M. G. Rinaldi ${ }^{2}$ and S. G. Revankar ${ }^{3}$}

${ }^{1}$ Dallas VA Medical Center and University of Texas Southwestern Medical Center, Dallas, TX, USA 
${ }^{2}$ University of Texas Health Science Center at San Antonio, TX, USA

${ }^{3}$ Harper University Hospital, Wayne State University, 3990 John R. St., 5 Hudson, Detroit, MI 48201, USA

tPresent address: 6560 Fannin, Suite 1540, Houston, TX 77030, USA.

Correspondence: S. G. Revankar (srevankar@med.wayne.edu)

CLSI (2002). Reference Method for Broth Dilution Antifungal Susceptibility Testing for Yeasts, approved standard, 2nd edn, M27-A2. Wayne, PA: Clinical and Laboratory Standards Institute.
Lee, M. K., Williams, L. E., Warnock, D. W. \& Arthington-Skaggs, B. A. (2004). Drug resistance genes and trailing growth in Candida albicans isolates. J Antimicrob Chemother 53, 217-224.

Marr, K. A., Rustad, T. R., Rex, J. H. \& White, T. C. (1999). The trailing end point phenotype in antifungal susceptibility testing is $\mathrm{pH}$ dependent. Antimicrob Agents Chemother 43, 1383-1386.

Pfaller, M. A. \& Diekema, D. J. (2004). Twelve years of fluconazole in clinical practice: global trends in species distribution and fluconazole susceptibility of bloodstream isolates of Candida. Clin Microbiol Infect 10 (Suppl. 1), 11-23.

Revankar, S. G., Kirkpatrick, W. R., McAtee, R. K., Fothergill, A. W., Redding, S. W., Rinaldi,
M. G. \& Patterson, T. F. (1998). Interpretation of trailing endpoints in antifungal susceptibility testing by the National Committee for Clinical Laboratory Standards Method. J Clin Microbiol 36, 153-156.

Rex, J. H., Nelson, P. W., Paetznick, V. L., Lozano-Chiu, M., Espinel-Ingroff, A. \& Anaissie, E. J. (1998). Optimizing the correlation between results of testing in vitro and therapeutic outcome in vivo for fluconazole by testing critical isolates in a murine model of invasive candidiasis. Antimicrob Agents Chemother 42, 129-134.

Sanglard, D., Ischer, F., Marchetti, O., Entenza, J. \& Bille, J. (2003). Calcineurin A of Candida albicans: involvement in antifungal tolerance, cell morphogenesis and virulence. Mol Microbiol 48, 959-976. 